biblio.ugent.be

The UGent Institutional Repository is the electronic archiving and dissemination platform for all UGent research publications. Ghent University has implemented a mandate stipulating that all academic publications of UGent researchers should be deposited and archived in this repository. Except for items where current copyright restrictions apply, these papers are available in Open Access.

This item is the archived peer-reviewed author-version of:

Title: The new Belgian law on biobanks: Some comments from an ethical perspective Authors: Sigrid Sterckx \& Kristof Van Assche

In: Health Care Analysis (in press, to be published 2011)

To refer to or to cite this work, please use the citation to the published version:

Sterckx, Sigrid \& Van Assche, Kristof (2011), "The new Belgian law on biobanks: Some comments from an ethical perspective", Health Care Analysis (in press, to be published 2011). 


\title{
The New Belgian Law on Biobanks - Some Comments from an Ethical Perspective
}

\author{
Sigrid Sterckx and Kristof Van Assche
}

\begin{abstract}
On 19 December 2008 the Official Journal of Belgium published the 'Law regarding the procurement and use of human body material destined for human medical applications or for scientific research purposes'. This paper will comment on various aspects of the Law: its scope of application (what is understood by 'body material'?); its concept of 'residual human body material' (with far-reaching implications for the type of consent required for research); the nature of actions with and uses of human body material that are explicitly prohibited; the right of donors to be informed of relevant information revealed by the use of their body material; and the special responsibilities placed on hospital ethics committees. As will be argued in this paper, several of these provisions are highly problematic from an ethical point of view, especially those relating to consent.

Meanwhile, the Minister of Public Health has asked the Belgian Advisory Committee on Bioethics for advice on the incorporation of the 'presumed consent' model, that applies to post mortem organ donation, into the biobank Law's provisions on post mortem removal and use of body material. This aspect of the Law effectively extends the 'presumed consent' regime, both from organs to body material in general, and from therapeutic uses to research uses.
\end{abstract}

Keywords: biobanks - ethics - Belgian law - research on human body material

\section{Introduction: Scope of application of the Law}

Biomedical research is said to rely increasingly upon the study of extensive collections of biological material (biobanks), e.g. of human tissues. In Belgium, biobanks are regulated by the 'Law regarding the procurement and use of human body material destined for human medical applications or for scientific research purposes'. This Law - which is intended inter alia to 
implement Directives 2004/23/EU, 2006/17/EU and 2006/86/EU - was adopted on 19 December 2008 and has entered into force on 1 December 2009, although a Royal Decree (executive order) regarding some of the Law's most important provisions is still awaited [10]. In this paper we will comment on various aspects of this Law. ${ }^{1}$

The Law is intended to detail the conditions for "the donation, retrieval, procurement, testing, processing, preservation, storage, distribution and use of human body material" (Art. 3(1)). It defines "human body material" as "every biological body material, including human tissues and cells, gametes, embryos, and foetuses, as well as substances extracted therefrom, whatever the degree to which they have been processed" (Art. 2(1)). ${ }^{2}$ Explicitly included in the scope of application of the Law are "the removal of, as well as all actions performed with stem cells, regardless of their source, inter alia [stem cells] from cord blood, peripheral blood, bone marrow and those of mesenchymal origin" (Art. 3(2)).

Explicitly excluded from the scope of the Law are: "(a) the removal of organs with a view to transplantation", already covered by the Law of 13 June 1986 regarding the retrieval and transplantation of organs; “(b) the actions, performed on blood and on elements and derivatives of blood", already covered by the Law of 5 July 1994 regarding blood and derivatives of blood of human origin; "(c) the removal of and actions performed with human body material with a view to an autologous application during a single operation"; “(d) the donation and the actions performed with a merely diagnostic purpose for the benefit of the person from whom the body material is removed, provided that the body material is not destined for another use" and the manipulation of, among other things, "hair, body hair, nails, urine, mother's milk, stools, tears and sweat" (Art. 3(3)). ${ }^{3}$

\footnotetext{
${ }^{1}$ We do not have the space here to comment on all the ethically relevant dimensions of the Law - e.g. we cannot go into its provisions regarding (non)commercialisation and privacy.

${ }^{2}$ Official versions of the Law exist only in Dutch and French. All quotes herein are translations by the authors. Any emphasis in quotes from the Law is added by the authors.

${ }^{3}$ It is also explicitly mentioned that the Law does not affect the provisions of the Law of 11 May 2003 regarding research on embryos in vitro, i.e. it does not apply to the removal of eggs in the context of assisted reproduction. Fertility centres are equated with banks for human body material (definition see infra) and actions with gametes and embryos may only be performed in such centres (Art. 3(4)).
} 


\section{"Banks for human body material" and "biobanks"}

In order to regulate the management of human body material, the Law creates two new structures: "banks for human body material" and "biobanks". A "bank for human body material" is defined as "the organisational structure, which carries out [the procuring, testing, processing, preserving, storing or distributing, including the import and export, of human body material]. This structure also has [...] the sole responsibility to decide on the allocation of human body material" (Art. 2(24)). Banks for human body material may only be established within the framework of accredited hospitals or faculties of medicine of universities. They are responsible for controlling the distribution of human body material and should ensure the largest possible availability of such material for medical and scientific use [2].

A "biobank" is defined in the Law as a "structure which stores and provides human body material, exclusively for scientific research, which is not intended for any application on humans" (Art. 2(27)). Such a structure may be established within the framework of accredited hospitals or faculties of medicine - implying that a bank for human body material can itself be a biobank - or it may be created by a private organization (e.g. a pharmaceutical company). Biobanks require an accreditation, awarded inter alia on the basis of a positive advice from an ethics committee [2].

\section{Actions with and uses of human body material that are explicitly prohibited by the Law}

The Law prohibits the following actions with human body material (Art. 8(1)):

"(1) The removal of, and each action with, human body material within the scope of this law, that is not performed with a preventative, diagnostic, or therapeutic purpose which is scientifically grounded in a precise manner or with a precise and relevant goal concerning scientific research the goal of which is specified";

"(2) Any use of human body material within the scope of application of this law, other than with a diagnostic, preventative, or therapeutic purpose which is scientifically grounded in a precise manner or with a precise and relevant goal concerning scientific research the goal of which is specified, and for which a positive advice has been given by an ethics committee as described in the law of 7 May 2004 regarding experiments on the human person"; 
“(3) Any removal of human body material whereby the expected consequences for the living donor are not proportional to the goal that is strived at"; and

"(4) The removal and storage of human body material, with a view to an autologous or later allogenic use, for a particular and identified recipient, except if (a) the person for whom the material is destined either exhibits a scientifically demonstrated exceptional risk, at the moment of the removal and/or the procurement, of a pathology for which the utility of the said actions is scientifically demonstrated, or suffers from such a pathology; or (b) the human body material remains available for therapeutic use in another person and is registered to be used in that way".

Interestingly, prohibiting the removal and storage of human body material with a view to later use for a particular and identified recipient - except if an exceptional risk exists for the recipient or if the material remains available for use in another (non-identified) person - implies inter alia that cord blood may not be stored exclusively for one's own or one's relatives future use, but must if stored remain available for non-specified third parties.

As mentioned in the Parliamentary debates preceding the adoption of the Law, this prohibition is founded on the principles of solidarity, non-discrimination and universal access to high quality healthcare [2].Indeed, private banks (for autologous use) undermine the effectiveness of public banks. By including this provision into the Law, Parliament obviously intended to outlaw the activities of certain cord blood banks such as Cryo-Save. This biobank freezes stem cells exclusively for autologous use, advertises itself as "Europe's leading stem cell bank" and claims to currently hold 130,000 samples (up from 5000 in 2002) [9].

In our view, biobanks of this nature should indeed not be allowed to operate anywhere. ${ }^{4}$ As the ethics advisory group of the President of the European Commission, the so-called European Group on Ethics in Science and New Technologies (EGE), already stated in 2004:

"The legitimacy of commercial cord blood banks for autologous use should be questioned as they sell a service, which has presently no real use regarding therapeutic options. Thus

\footnotetext{
${ }^{4}$ For various compelling arguments against private cord blood banking, see [13, 4].
} 
they promise more than they can deliver. The activities of such banks raise serious ethical criticisms." [5]. ${ }^{5}$

\section{The donors' right to relevant information regarding their health}

Another notable feature of the Law is that donors are granted the right to be informed if the use of their body material yields important health-related information. According to Art. 11(1): "If, in case of an action performed on human body material or the use of human body material, analyses provide meaningful information regarding the health status of the donor, the donor has a right to this information. [...] The physicians who learn such information in the context of an action with or use of the material, the guardians of the human body material and the chief physician of the hospital where the removal took place are, each in the context of their function and role, responsible for the application of [this provision]". The donor's right not to know is recognized by Art. 11 (2), in accordance with the 2002 Act on Patients' Rights.

In our view, the inclusion into the Law of a provision explicitly recognizing a donor's right to important health-related information is to be applauded, not least on the basis of reciprocity - the donor made her material available for research use, so it is only reasonable to require those who benefit from the availability of the material to ensure that if relevant information is revealed, the donor receives that information. We obviously agree with many commentators that this demands time and effort from the researchers/physicians involved, but not with the conclusion drawn by some that the donors' interests must be sacrificed for the sake of the "efficiency" of research.

However, the wording of the relevant provision in the Belgian Law immediately gives rise to a host of questions. To mention but a few: What would count as "meaningful" information?; What if diverging interpretations exist regarding the relevance of the information?; What if the "meaningful" information is discovered by researchers who are not physicians?; and What if the donor can no longer be contacted?

\footnotetext{
${ }^{5}$ Sadly, however, at the same time Cryo-Save was one of the partners in an EU funded $6{ }^{\text {th }}$ Framework Program project (Crystal).
} 
As to the donor's right not to know, the question arises as to how a donor is supposed to know whom to advise that she wishes to exercise this right (as provided by the 2002 Act on Patients' Rights to which the Law refers).

Moreover, ascribing responsibility to three different (sets of) actors seems to entail a significant risk of what social psychologists such as Albert Bandura (2002) call "diffusion of responsibility", which obscures the individual responsibility of everyone involved and may result in nobody providing the information to the donor even if aware that it would clearly be in the donor's interest [1].

\section{Consent from living donors to uses of human body material for research purposes}

The Law contains an extensive chapter on donor consent, the provisions of which "do not apply if the removal of and all actions with the human body material exclusively take place for a scientifically accepted directly preventative, diagnostic or therapeutic purpose for the sake of the donor" (Art. 9). Hence, if the material is also or only used for research purposes, the consent provisions are applicable.

\section{Removal of body material from minors, prolonged minors and incompetent persons}

The Law stipulates as a general principle that "the removal of human body material from living humans can only be carried out on a non-minor donor who has consented to this in advance [in accordance with Art. 10(5) - discussed below]" (Art. 10(1)). However, "If the removal of human body material from living humans normally can not have serious consequences for the donor and the removal concerns cells and tissues which regenerate, or if the removal takes place for autologous purposes, it can, despite (1), be carried out on minors and non-minors who have the status of prolonged minors or who are incompetent" (Art. 10(3)). Such removal requires the consent of the donor's representative (in accordance with the 2002 Act on Patients' Rights).

The latter provision is clearly not in accordance with the Council of Europe's Convention on Human Rights and Biomedicine of 4 April 1997 [3]. ${ }^{6}$ Art. 20(2) of this Convention allows "the

6 This Convention (commonly referred to as the 'Oviedo Convention') has not been ratified by Belgium, mainly
because of its Art. 18(2), forbidding the creation of human embryos for research purposes. The travaux préparatoires of
the biobank Law document a discussion in Parliament regarding this inconsistency with the Oviedo Convention. The 
removal of regenerative tissue from a person who does not have the capacity to consent" only when:

"(i) there is no compatible donor available who has the capacity to consent;

(ii) the recipient is a brother or sister of the donor;

(iii) the donation must have the potential to be life-saving for the recipient;

(iv) the authorisation [...] has been given specifically and in writing, in accordance with the law and with the approval of the competent body;

(v) the potential donor concerned does not object".

\section{Removal of body material from non-minors}

The consent provisions to be observed in cases of non-minor donors (i.e. in standard cases) differ in morally significant ways, depending on the 'type' of use proposed for the body material ("primary use" versus "secondary use") and on whether the material is "residual" or not.

Proceeding from the general principle that human body material can only be removed from living humans after consent has been given (Art. 10(1) above), the Law then goes on to specify that: "The consent for the removal and any use of body material of living humans [...] must be given in an informed, conscious and free fashion. The donor [...] must be systematically informed of the use of the body material and the purpose of such use, and must consent to this in advance. This consent must be given in writing and the object and scope of the consent must be specified. The consent must be dated and signed by the person or persons whose consent is required. The consent for the use of the material can be withdrawn at any time before the material has been subjected to any action after having been procured" (Art. 10(5)).

However, as noted above, the Law distinguishes between "primary" and "secondary" uses of human body material. The former, according to Art. 2(29), concern "any use of the human body material to which the donor has explicitly and specifically consented in the context of the removal", whereas "secondary" use is defined as "any other use of human body material than that

Minister of Public Health's response was that this Convention is overly restrictive and prevents the removal of tissues and cells for research purposes. We do not have the space to elaborate on this issue here. 
to which the donor has [explicitly and specifically] consented in the context of the removal" (Art. 2(30)).

In cases of "secondary" use, Art. 20(1) requires that "the donor must be informed [...] and his explicit written consent must be obtained in advance [in accordance with Art. 10(5) above]". So, at first sight, the Law seems to prescribe an 'informed consent' (or 'explicit consent') regime for uses of human body material for research purposes. However, it is added in the same provision that: "In case it is impossible to ask for consent to the secondary use, or should this question be exceptionally inappropriate, secondary use can take place after an ethics committee [in accordance with the law on experimentation on human beings] has issued a positive advice".

Moreover, in contrast with its provisions on informed/explicit consent for the primary and secondary use of human body material, the law posits presumed consent for the use of "residual human body material" for purposes of scientific research. This category of "residual" material is defined as "the part of the body material that is removed with a view to diagnosis or treatment of the donor which, after a sufficient and relevant part is stored for making, refining or completing the diagnosis or treatment of the donor on the basis of new scientific information, is superfluous with regard to these purposes and may thus be destroyed" (Art. 2(33)). Consent for research uses of such material "is presumed to have been given insofar as the donor [or a surrogate] has not announced her refusal [to the doctor responsible for the removal or to the senior doctor of the hospital] prior to the initiation of any action with the residual human body material". It is added that: "For the application [of that provision], the intended use of the material as well as the possibility for the donor or surrogate to refuse, has to be notified in advance in writing to the donor or surrogate" (Art. 20(2)).

In our view, these provisions are highly problematic. Regarding in particular the establishment of a 'presumed consent' regime for the use of "residual" body material for research purposes, we would argue that a "right to refuse" is not enough and that informed consent for the use of biological material for a diagnostic and/or therapeutic purpose cannot be interpreted as an implicit authorisation to use the material for research purposes. In our view, consent to use material for research should not be taken as implicit but should be given explicitly by the donor. 
In the consent regime we would advocate, each body material sample would be assigned a code when it is procured, clearly showing if the donor:

- has not given consent for the use of the material for scientific research (e.g. a code starting with or ending in A); or

- has given consent for the use of the material for research concerning the disease(s) the donor suffers from (e.g. a code starting with or ending in B); or

- has given consent for the use of the material for scientific research in general (e.g. a code starting with or ending in C).

Thus, the person concerned should receive clear and comprehensible information as to why it may be desirable for her body material to be used in research. ${ }^{7}$ On the basis of this information, and after being given an opportunity to ask questions, the person must be allowed to decide whether or not to agree to the use of her material for research, with the option being available in the former case (i.e. agreeing) to distinguish between, on the one hand, use for research concerning the disease(s) from which the donor suffers (if any) and, on the other hand, use for scientific research in general. The person concerned must equally be allowed to decide, in either of the two cases of agreement just mentioned, whether she agrees to the body material being used in projects of a commercial nature, and this decision should also be reflected in the coding of the material (e.g. B- or B+; C- or C+).

If the person concerned is also being treated - with treatment and research potentially being combined - we deem it necessary to explain clearly that any opposition to the use of the material for research purposes would have no influence whatsoever on the treatment received by the person. This may reduce the likelihood that patients feel obliged to consent, in order not to jeopardize (the quality of) their treatment.

The frequently mentioned argument that asking for consent for the use of body material for research requires too much time and involves too many practical problems, is not justified in our view, given that in all cases where the biological material is taken for diagnosis and/or treatment,

\footnotetext{
${ }^{7}$ We wish to emphasise that, when we use the words "her" or "his" body material, we are certainly not suggesting that people have or should have property rights in their body or in their body material (detached or not). Rather, our arguments are based on persons' rights to control/ decide what may be done to body material procured from them.
} 
at the moment when informed consent is requested for procuring the material for diagnosis and/or treatment, consent may also be explicitly requested for potential use of the material for research purposes.

Of course we are aware that one of the reasons why so many in the biomedical field oppose the idea of asking consent for use of body material for research purposes is that in a great many cases the 'other' consent (i.e. for procuring the body material for diagnostic and/or therapeutic purposes) is not even asked for, so requesting consent for research uses would not just be a matter of asking a second question after the first. However, one cannot justify a wrongful omission on the basis of an (earlier) wrongful omission.

It could be objected that requiring informed consent to use body material for research (whether research in general or research regarding particular diseases) would either be an impediment to research or cannot generate a valid consent because in order for a consent to be valid it must not only be explicit but also very specific as to the nature and purpose of the research. According to this line of reasoning, if not specific the consent would be invalid and if specific it would be valid but the researchers would be obliged to keep going back to the donor for new specific consents for any new research use (since at the time of procurement of the body material scientists can not foresee how the field will develop in the future and hence which research uses of the material may become possible), thus significantly raising the price and slowing the pace of research.

However, we are not convinced by this line of reasoning. In an ideal world, consent would indeed be very specific as to the nature and purpose of the research (as prescribed for example by the World Medical Association's Declaration of Helsinki, which since its most recent revision in 2008 also applies to identifiable human body material) [14]. In the real world, it seems to us to be far more preferable for donors to have a guaranteed opportunity to give a somewhat less specific consent to research use of their body material than for donors simply to be presumed to have agreed to research use, merely because they have agreed to having body material taken for diagnosis or treatment.

Admittedly, the question then arises whether the less specific consent our proposal would allow may still legitimately be called an 'informed' consent or even a 'consent' tout court. As Hofmann, Solbakk and Holm have rightly noted [8]: 
$[\mathrm{U}]$ sing the term consent in situations that do not comply with the standard requirements for consent, such as understanding the scope and consequences of research, does undermine the concept of consent. It could therefore be argued that the eagerness to stick to the term "consent" even though the premises for consent are not met, is much less because of the interest of protecting research persons, than covering moral challenges by means of a device. This changes the objective of the protective aspirations of consent from the research person to the researcher. [...] If understanding the scope and consequences of research is a sine qua non for consent, then consent to biobank research of a general and unspecified kind cannot be obtained, neither of a narrow brand nor of a broad one [and then] [t]here can be no informed consent because the research person cannot know important aspects of future research with respect to the biological material $[\ldots]]^{8}$

Indeed, in relation to our proposal it may be more appropriate to use the term 'explicit authorisation' or 'explicit consent' instead of 'informed consent'. The explicit (as opposed to passive or presumed) character of the authorisation or consent is crucial, in our view, for it is important to recall that the ethical basis for the requirement for consent is respect for autonomy. Hence authorisation or consent models should not be "diluted" to the extent that autonomy no longer even has a place in the picture [7]. Each person has values which translate into aspirations and life plans. These values may conflict with the working methods and/or the goals of certain types of scientific research. Hence, even though biobank research, as compared with clinical research, may well involve limited health risks for donors, it may pose risks of 'moral' harms that are unrelated to privacy or 'informational' issues and these seem to be ignored by most commentators. The "negligible risk" argument that is frequently invoked to defend the claim that in the case of biobank research there is no need to adopt strict measures such as explicit consent

\footnotetext{
${ }^{8}$ They propose an alternative which they call "conditional authorization", a kind of contract that "should include explicit clauses" on: the moral and legal status of biological material; consequences with respect to risks and benefits; relationship to other sources of information; conditions for initiating further research on the basis of existing biobank material; and what would happen if any of the parties to the contract breach the conditions [8]. We do not advocate such an approach, for in our view it opens issues to negotiation which should not be negotiable, e.g. for example questions of ownership of the material in the biobank and of remuneration in the event of commercial potential. We believe this would lead to the unsavoury practice of donors authorising any kind of research and discarding any moral or other reservations they may have in hope of some revenue from commercial applications. A "conditional authorization" procedure would only seem desirable in the presence of a binding and effectively enforced legal framework which prevents such an outcome.
} 
to protect participants, and that blanket or even presumed consent is sufficient, is thus unconvincing (even though we do not contest that biobank research poses less physical risk than clinical research).

If scientists think that they have valid reasons to use particular biological material for research, they are fully entitled to explain to the potential donor why the research they envisage is crucial and why the person's contribution (via the provision of body material) would be of the utmost importance. However, this does not give scientists the right, in place of the interested party, to take the decision to use the material. The potential donor must have the opportunity of ascertaining whether the proposed use of the material for research is contrary to her moral values. If this opportunity is taken away from her and the decision is taken in her place, "in the interests of science", then the material is being used to achieve an objective which is not her own and, consequently, the decision violates her dignity. It should also be noted that anonymising or coding the body material does not change this - the argument that moral reservations are no longer applicable if the material is anonymised or coded, so as to offer solid guarantees in terms of respect for privacy, totally misses the point because this offers guarantees only in terms of respect for privacy and does not in any way satisfy the need to respect persons and their autonomy.

It may well be legitimate to expect citizens to contribute to progress in research, but one should never force this contribution by presuming consent instead of asking for it [12]. Admittedly, in some countries a large majority of the persons concerned are not, when asked, opposed to giving consent to research use [6]. However, we cannot and must not assume that everyone will agree. Again, it is highly desirable that citizens be informed of the value of certain kinds of research and encouraged to contribute, inter alia by donating body material - but this does not authorise researchers to use body material for research "in the name of science" without having first obtained the consent or authorisation of the person concerned.

Some might argue that the Belgian biobank Law does require that: "For the application [of the provision regarding presumed consent], the intended use of the material as well as the possibility for the donor or surrogate to refuse, has to be notified in advance in writing to the donor or surrogate" (Art. 20(2)). This may at first sight create the impression that an absence of refusal will indeed imply a 'valid' consent. However, it has already become clear that most, if not all, 
Belgian hospitals intend to meet the advance notification requirement simply by adding a few words to their patient information brochure. In addition to the fact that this information is likely to be so limited and vague that it cannot possibly form the basis of a valid consent, the question arises as to whether the law grants persons who are too frail to read or insufficiently educated to understand the written information any rights at all to refuse research use of their body material.

\section{Special responsibilities placed on hospital ethics committees}

The Law also charges ethics committees with far-reaching responsibilities. Art. 21 provides that: "Any secondary use of the human body material, as well as the specific purpose thereof, must be the subject of a preliminary positive advice by an ethics committee [...]. [In case it is impossible to ask the donor's consent to the secondary use, or should this question be exceptionally inappropriate], the same ethics committee shall issue a global advice. [...]".

Moreover, it is specified in the same provision that the ethics committee must provide advice on "at least" the following issues:

"1) the relevance of the secondary use and its design";

"2) the respect for the law and its executive decrees";

"3) the adequacy of the communicated information and the sufficiency of the specificity and scope of the consent";

"4) [if the case occurs], the impossibility of asking consent for the secondary use or the exceptionally inappropriate character of the question."

The main problem with this provision is that the responsibilities listed are so extensive that it will be virtually impossible for the existing, heavily overburdened, ethics committees to meet them. Adding these responsibilities to their tasks will certainly not improve the quality of their decision-making. 
Post mortem research uses of human body material: the problematic incorporation of the 'presumed consent' principle applicable to post mortem removal of organs for transplantation

Concerning post mortem removal of human body material, the Law stipulates that "For the removal after death, the articles 10 to 14 of the law of 13 June 1986 [amended] regarding the removal and transplantation of organs apply" (Art. 12).

This results in a striking twofold extension of the "presumed consent" regime that governs cadaveric organ transplantation in Belgium: first, an extension from post mortem removal of organs to post mortem removal of any human body material that falls under the scope of this Law, and secondly, an extension from post mortem removal for transplantation (i.e. therapeutic) purposes to post mortem removal for research purposes.

In view of the comments made in the previous section as to the illegitimacy of extrapolation from consent for uses of body material for therapeutic purposes to consent for research uses, it is to be welcomed that the Minister of Public Health has asked the Belgian Advisory Committee on Bioethics to give advice regarding the implications as well as the desirability of incorporating this provision into the biobank Law [11]. ${ }^{9}$

\section{Conclusion}

The Belgian biobank Law has some features that, in our view, are laudable from an ethical point of view. For example, private biobanks, established to store human body material for later autologous use, are explicitly prohibited, in order to enable access to high quality healthcare for everybody. Some other praiseworthy provisions of the Law can, however, be easily circumvented. For example, while donors are granted an explicit right to receive important health-related information that is revealed during research, ascribing this obligation

\footnotetext{
${ }^{9}$ We cannot elaborate on these important questions here, but two particular concerns deserve a brief mention. Firstly, because of objections to research use, it is possible that more people will opt out from post mortem donation, so reducing the already limited supply of transplantable organs. Secondly, where the person has not expressed her wishes regarding post mortem organ donation, it would seem that post mortem attempts to secure consent from relatives are likely to stress transplantation and perhaps minimize or ignore research uses which would also be envisaged.
} 
simultaneously to three different sets of actors may result in none taking responsibility. Still other aspects of the Law are clearly problematic, especially those concerning the introduction of a presumed consent regime for research uses of "residual" body material. The person concerned is denied the opportunity to determine whether the use of her body material for (particular) research goals is contrary to her moral values. This amounts to a violation of autonomy and human dignity in the interests of science. To remedy this shortcoming, while at the same time realising that informed consent as prescribed in the context of clinical research is too demanding as a standard for biobank research, we propose a consent or authorisation regime that offers potential donors the right to decide in advance - on the basis of the best available information at the time whether they agree to their body material to be used in future research, with options regarding research goals and possible commercialisation clearly spelled out.

\section{References}

1. Bandura, A. (2002). Selective moral disengagement in the exercise of moral agency. Journal of Moral Education, 31(2), 101-119.

2. Committee on Public Health and Environment of the House of Representatives. Report of the debates on the proposed biobank law, DOC 52 1409/(2007/2008)/004, 28 November 2008.

3. Council of Europe. Convention for the protection of human rights and dignity of the human being with regard to the application of biology and medicine, Oviedo, 1997. Published online at: http://conventions.coe.int/treaty/en/treaties/html/164.htm.

4. Dickenson, D. (2008). Body shopping - The economy fuelled by flesh and blood. Oxford: Oneworld.

5. European Group on Ethics in Science and New Technologies (2004). Opinion 19. Published on-line at: http://europa.eu.int/comm/european_group_ethics/docs/avis19_en.pdf.

6. Hansson, M.G. (2007). For the safety and benefit of current and future patients. Pathobiology, 74, 198-205.

7. Hofmann, B. (2009). Broadening consent - and diluting ethics? Journal of Medical Ethics, $35,125-129$. 
8. Hofmann, B., Solbakk, J.H. \& Holm, S. (2009). Consent to biobank research: One size fits all? in Solbakk, J.H., Holm, S. \& Hofmann, B. (2009). The ethics of research biobanking. Dordrecht: Springer, 3-23.

9. http://www.cryo-save.com [last checked on 6 August 2010].

10. 'Law regarding the procurement and use of human body material destined for human medical applications or for scientific research purposes', Published on-line at: http://www.ejustice.just.fgov.be/cgi_loi/change_lg.pl?language=nl\&la=N\&cn=2008121944\& table_name=wet (Dutch) and at http://www.ejustice.just.fgov.be/cgi_loi/change_lg.pl?language=fr\&la=F\&cn=2008121944\&t able_name=loi (French).

11. Onkelinkx, L. Letter to the Belgian Advisory Committee on Bioethics, 12 February 2010.

12. Savulescu, J. (2002). No consent should be needed for using leftover body material for scientific purposes - Against. British Medical Journal, 325, 649-651.

13. UK Royal College of Obstetricians and Gynaecologists' Scientific Advisory Committee (2006). Umbilical cord blood banking. Published on-line at: http://www.rcog.org.uk/files/rcog-corp/uploaded-files/SAC2UmbilicalCordBanking2006.pdf.

14. World Medical Association's Declaration of Helsinki. Ethical principles for medical research involving human subjects. Sixth revision, 59th meeting, Seoul, 2008. Published on-line at: http://www.wma.net/en/30publications/10policies/b3/17c.pdf. 